\title{
Theoretical studies of electronic structure and structural properties of anhydrous alkali metal oxalates
}

\author{
Part I. Electronic structure and electron density topology calculations
}

\author{
A. Koleżyński • A. Małecki
}

Received: 8 January 2013/Accepted: 8 March 2013/Published online: 2 April 2013

(C) The Author(s) 2013. This article is published with open access at Springerlink.com

\begin{abstract}
The results of first principles calculations of band structure, density of states, and electron density topology of alkali metal oxalates are presented. The calculations have been carried out with WIEN2k ab initio program, using highly precise full potential linearized augmented plane wave method within density functional theory formalism. Calculated total electron density has been used in calculations of its topological properties (according to Bader's quantum theory of atoms in molecules formalism) and Cioslowski and Mixon's topological bond orders. The obtained results show important similarities between electronic structure and electron density topology for all analyzed structures with electronic structure close to Fermi energy typical for ionic compounds and bonding which is mainly covalent within the oxalate anion (with partly ionic character of carbon-oxygen bonds) and strongly ionic between oxalate anion and cationic sublattice. These results have been used as a basis for theoretical analysis of thermal decomposition process described in detail in part II of this paper (where also the results of additional calculations of atomic and bond valences, bond strengths and strains are presented).
\end{abstract}

Keywords FP-LAPW ab initio calculations · Electron density topology $\cdot$ Bond orders $\cdot$ Thermal decomposition

A. Koleżyński $(\bowtie) \cdot$ A. Małecki

Faculty of Materials Science and Ceramics, AGH University

of Science and Technology, Al. Mickiewicza 30,

30-059 Kraków, Poland

e-mail: andrzej.kolezynski@agh.edu.pl

\section{Introduction}

Anhydrous alkali metal oxalates $\mathrm{M}_{2} \mathrm{C}_{2} \mathrm{O}_{4}$ form an interesting group of compounds with very similar layered crystal structures and well-defined oxalate anions as an independent entity surrounded by metallic cations, decomposing thermally_unlike transition metal oxalates-via two step process with respective carbonate as transition product [1-12]:

$\mathrm{M}_{2} \mathrm{C}_{2} \mathrm{O}_{4} \rightarrow \mathrm{MCO}_{3}+\mathrm{CO}$

$\mathrm{MCO}_{3} \rightarrow \mathrm{MO}+\mathrm{CO}_{2}$.

Despite many experimental results available, there is still lack of consistent theoretical description and explanation of the pathways of thermal decomposition of these compounds. One can expect, however, that the crucial role here is played by the properties of electronic structure and chemical bonding. Thus theoretical studies of fundamental features of electronic structure, total electron density (topological analysis), and chemical bonding (bond order, bond valence, bond strains, etc.) carried out for this group of compounds should, in principle, allow explaining the observed pathway of thermal decomposition process (or at least provide some important information about the relations between electronic and crystal structure and bonding properties and pathway of thermal decomposition process).

Recently, in a series of papers [13-19], we have proposed theoretical approach, based on the topological analysis of electron density (Bader's Quantum Theory of Atoms in Molecules [20] formalism) obtained from first principles FP-LAPW calculations and structural and bonding properties-bonds valence, bond strength and stresses associated with deviation of given structure from ideal one (Brown's Bond Valence Method [21] founded on Pauling's "electrostatic valence rule" [22]). Our previous results obtained 
mostly for transition metal oxalates suggest that such approach can give us additional insight into the thermal decomposition process and help not only to explain thermal decomposition path in given oxalate, but also-to some extent predict such most probable path for the compounds for which experimental results are unavailable.

In this paper, the results of similar analysis, carried out for alkali metal oxalates, are presented (methods used for the calculations and analysis have been described in detail in $[13,14])$. The paper is divided into two parts - first one devoted to electronic structure and electron density topology analysis and the second to bonding properties and thermal decomposition process analyzed in the light of entirety of the obtained results.

\section{Computational details}

The electronic structure calculations for anhydrous alkali metals oxalates have been performed using WIEN2k FP-LAPW (Full Potential Linearized Augmented Plane Wave Method) package [23], within Density Functional Theory (DFT) formalism [24-29]. All calculations have been carried out for five different oxalates ( $\mathrm{Li}, \mathrm{Na}, \mathrm{K}, \mathrm{Rb}$, $\mathrm{Cs})$. In case of rubidium oxalate, respective calculations have been done for two phases ( $\alpha$ and $\beta$ ). The following parameters have been used in calculations: $500 k$-points, cut-off parameter $R k_{\max }=7.5$, GGA-PBE exchange-correlation potential [30], the values of muffin-tin radii $\left(R_{\mathrm{i}}\right)$ [a.u.]: Me, $1.7 ; \mathrm{O}, 1.17 ; \mathrm{C}, 1.17$ (except for both rubidium oxalate phases for which we've chosen $R_{\mathrm{i}}=1.12$ for oxygen and carbon atoms to avoid sphere overlapping, forbidden in this method) and the convergence criteria for SCF calculations set to $\Delta E_{\mathrm{SCF}} \leq 10^{-5} R y$ for total energy and $\Delta \rho_{\mathrm{SCF}} \leq 10^{-5} e \mathrm{au}^{-3}$ for electron density topology analysis. The crystal structure parameters used in calculations are listed in Table 1.

Crystal structure of anhydrous alkali metal oxalates

Four of the structures analyzed in this paper exhibit monoclinic symmetry $P 2{ }_{1} / c$, SG no. 14 (Li, Na, $\alpha$-Rb, Cs oxalates) while the remaining two $(\mathrm{K}, \beta-\mathrm{Rb})$ have orthorhombic

Table 1 Anhydrous alkali metal oxalates crystal structure data [31]

\begin{tabular}{|c|c|c|c|c|c|c|}
\hline Structure & $\begin{array}{l}\text { Space } \\
\text { group }\end{array}$ & $\mathrm{a} / \AA ̊$ & $\mathrm{~b} / \AA$ & $\mathrm{c} / \AA$ & $\beta /^{\circ}$ & $\mathrm{V} / \AA^{3}$ \\
\hline $\mathrm{i}_{2} \mathrm{C}_{2} \mathrm{O}_{4}$ & $P 2_{1} / n$ & 3.400 & 5.156 & 9.055 & 95.600 & 157.98 \\
\hline $\mathrm{Na}_{2} \mathrm{C}_{2} \mathrm{O}_{4}$ & $P 2_{1} / n$ & 3.449 & 5.243 & 10.375 & 92.660 & 187.41 \\
\hline $\mathrm{K}_{2} \mathrm{C}_{2} \mathrm{O}_{4}$ & Pbam & 10.912 & 6.116 & 3.440 & 90 & 229.57 \\
\hline$\beta-\mathrm{Rb}_{2} \mathrm{C}_{2} \mathrm{O}_{4}$ & Pbam & 11.288 & 6.295 & 3.622 & 90 & 257.37 \\
\hline$\alpha-\mathrm{Rb}_{2} \mathrm{C}_{2} \mathrm{O}_{4}$ & $P 2_{1} / c$ & 6.328 & 10.455 & 8.217 & 98.016 & 538.30 \\
\hline $\mathrm{Cs}_{2} \mathrm{C}_{2} \mathrm{O}_{4}$ & $P 2_{1} / c$ & 6.622 & 11.004 & 8.613 & 97.139 & 622.65 \\
\hline
\end{tabular}

symmetry Pbam, SG no. 55 (since detailed pictures of all of these structures can be found in [31], due to space limitation, they are not repeated here and only local environments of oxalate anions in all six structures with respective bond labels used in the following analysis are presented in Fig. 1 -for potassium and $\beta$-rubidium as well as for $\alpha$ rubidium and cesium anhydrous oxalates, these data are identical, thus only one picture for each pair is shown).

The structure of anhydrous lithium oxalate consists of strongly deformed tetrahedral $\mathrm{LiO}_{4}$, connected alternately via corners to form chains which, in turn, are connected to each other by oxalate anions. Locally, every $\mathrm{LiO}_{4}$ tetrahedron is surrounded by three (two uni- and one bidentate) oxalate groups. Anhydrous sodium oxalate structure can be depicted as double chains formed by edge sharing, deformed $\mathrm{NaO}_{6}$ octahedra (each octahedron within given chain shares one edge with its neighbors and two with octahedra in adjacent chain). Every such double chain is connected with four neighboring double chains by means of common corners of respective octahedra. All oxalate anions are built into existing channels within such substructure formed by octahedra. Locally, each pair of octahedra is surrounded by six (four uni- and two bidentate) oxalate anions. As a result, every octahedron is surrounded effectively by five (four uni- and one bidentate) oxalate anions, and each oxalate anion is surrounded by six octahedra.

Anhydrous potassium and $\beta$-rubidium oxalates have identical crystal structures which can be described as double chains parallel to $z$ axis, built from deformed, face sharing $\mathrm{KO}_{8}\left(\beta-\mathrm{RbO}_{8}\right)$ cubes. These double chains are connected with four similar neighboring double chains via shared edges creating spatial channel network, filled with oxalate anions. Each pair of cubes is surrounded by eight (for uni- and four bidentate) oxalate anions; each cube is effectively surrounded by six oxalate anions, while every oxalate anion is surrounded by 12 cubes.

Similarly, the last two structures $(\alpha-\mathrm{Rb}$ and $\mathrm{Cs}$ anhydrous oxalates) are identical and have monoclinic symmetry. The main difference in comparison with lithium and sodium oxalates is the spatial conformation of oxalate anions, which are, here, not planar, but $\mathrm{COO}^{-}$groups are perpendicular to each other (this is the preferred conformation for isolated anion, as predicted from ab initio calculations). What is more, these structures are significantly more complex than those described above for lithium and sodium oxalates and can be described as layers perpendicular to $x$ axis, connected by oxalate anions.

\section{Results}

Electronic structure

The total and partial densities of states calculated for all structures under study are presented in Fig. 2. Due to paper 


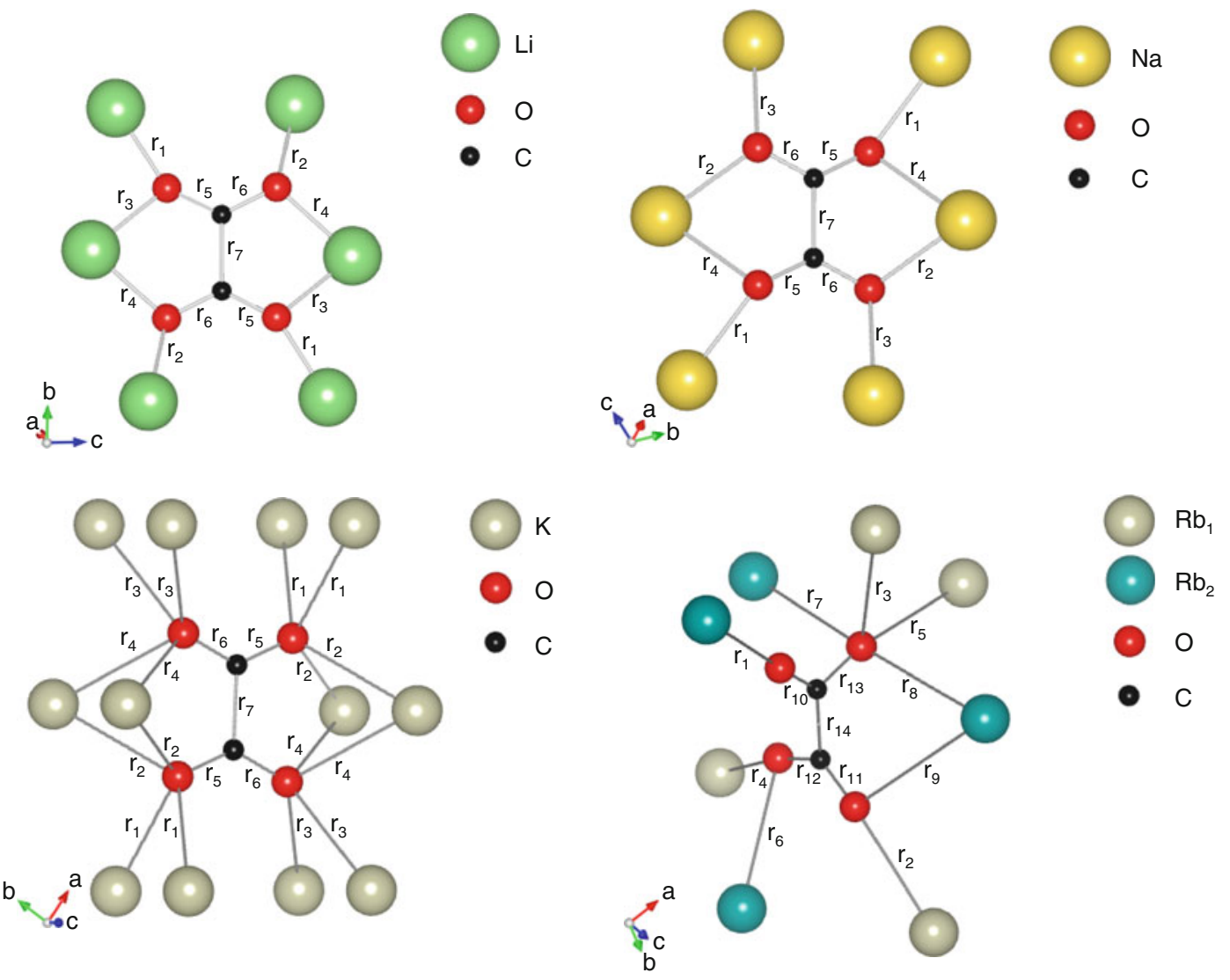

Fig. 1 Oxalate anion environments for $\mathrm{X}_{2} \mathrm{C}_{2} \mathrm{O}_{4}(X=\mathrm{Li}, \mathrm{Na}, \mathrm{K}, \beta-\mathrm{Rb}, \alpha-\mathrm{Rb}, \mathrm{Cs}$; $\mathrm{Li}-$ top left, $\mathrm{Na}-$ top right, $\mathrm{K}$, $\beta$ - $\mathrm{Rb}-$ bottom left and $\alpha$ - $\mathrm{Rb}$, Cs-bottom right)

size limitations, there is no place for detailed analysis of the obtained electronic structures (such an analysis will be published elsewhere), but one can easily see that in all cases, DOS and PDOS-es are quite similar, with sharp peaks (indicating small dispersion of respective energy bands) which are typical for ionic structures. Almost all states are filled mutually exclusively by electrons originating from alkali metal cations and-together-carbon and oxygen. This indicates that there are, in fact, no significant orbital overlapping and bond forming between alkali metal cations and oxygen atoms. On the other hand, oxygen and carbon states overlap significantly, indicating strong bonding. From these results, the following picture emerges: oxalate anions are independent, well-defined entities with covalent and ionic-covalent bonds between carbon-carbon and carbon oxygen atoms, respectively, interacting by means of the electrostatic forces with cationic sub-lattice.

\section{Electron density topology}

The total electron density obtained in SCF calculations has been used in topological analysis carried out within Bader's Quantum Theory of Atoms in Molecules formalism.
According to Bader's formulation, every bond critical point $\mathrm{BCP}$, can be described by its position, electron density in this point, Hessian matrix eigenvalues $\lambda_{1}, \lambda_{2}, \lambda_{3}$, and Laplacian $\nabla^{2} \rho(r)$, defined as a trace of Hessian matrix. The negative values of the Laplacian $\left(\nabla^{2} \rho(r)<0\right)$ are characteristic for covalent bonding (charge is concentrated between bonded atoms), while positive ones are characteristic for ionic bonding (charge depletion in bond region). In addition, bond ellipticity defined as $\varepsilon=\left|\lambda_{1}\right| \lambda_{2}-1 \mid$, measures how much the bond is elongated in $e_{1}$ direction, compared to $e_{2}$-large value of ellipticity indicates that bond has a significant $\pi$-character. Bader introduced also the concept of local electronic energy density $H_{\mathrm{e}}(r)=G(r)+V(r)$, which can be expressed in terms of electrostatic potential, electron density and its Laplacian only, by the formula $H_{\mathrm{e}}(r)=1 / 2\left[V(r)+1 / 4 \nabla^{2} \rho(r)\right]$ (where values of potential and Laplacian are expressed in atomic units). The sign of $H_{\mathrm{e}}(r)$ uniquely indicates whether the kinetic or potential energy dominates in a given region in space-negative value of $H_{\mathrm{e}}(r)$ means that the potential energy dominates and the accumulation of electrons is stabilizing in this region of space (this immediately implies that the condition $\nabla^{2} \rho(r)>0$ for the inter-nuclear space is not sufficient for a system to become unbounded, since the electron 

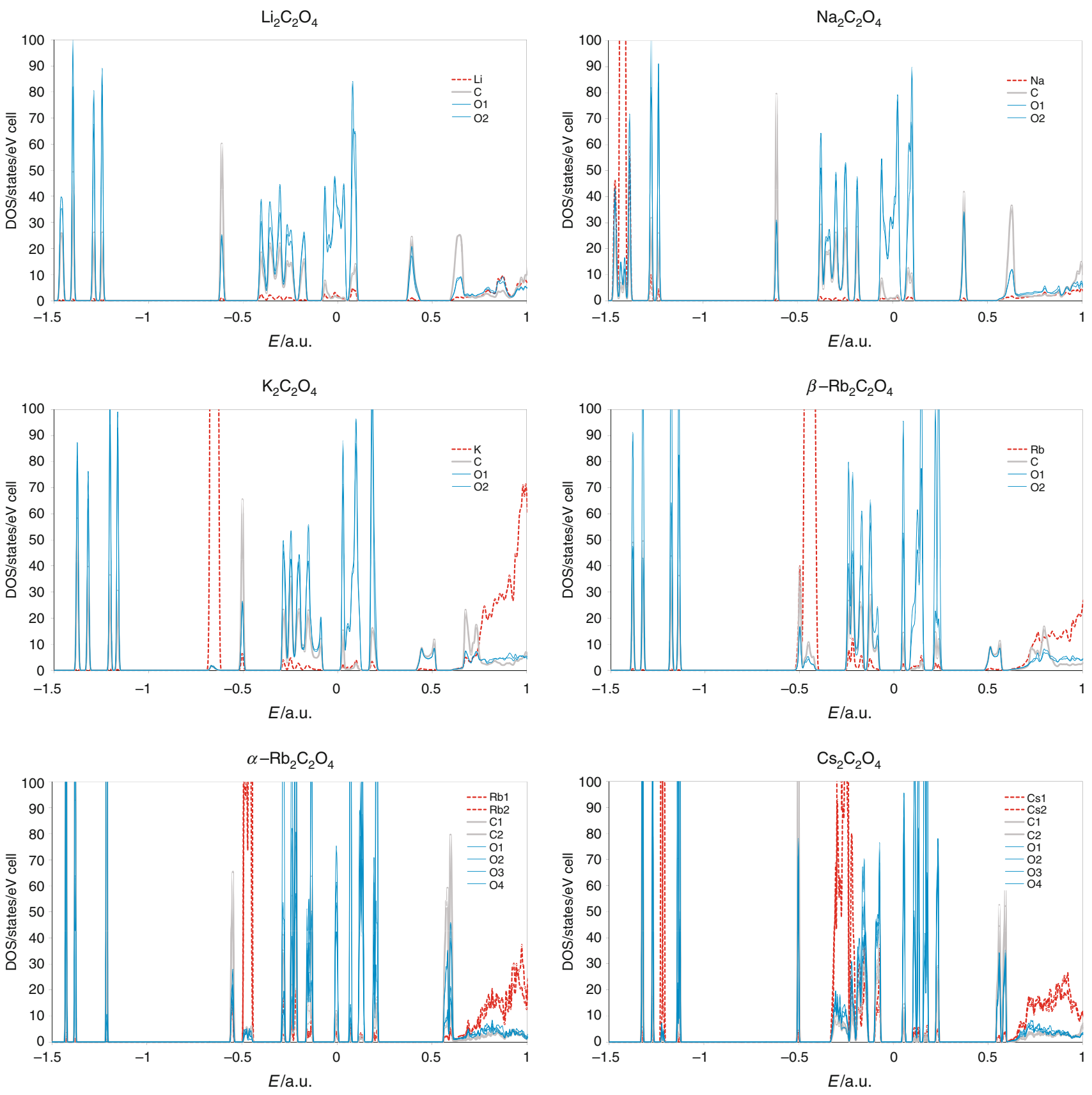

Fig. 2 Density of states (total and projected onto particular atoms) calculated for $\mathrm{X}_{2} \mathrm{C}_{2} \mathrm{O}_{4}(\mathrm{X}=\mathrm{Li}, \mathrm{Na}, \mathrm{K}, \beta-\mathrm{Rb}, \alpha-\mathrm{Rb}, \mathrm{Cs} ; \mathrm{Li}, \mathrm{Na}-$ top, $\mathrm{K}$, $\beta-\mathrm{Rb}-$ middle and $\alpha-\mathrm{Rb}, \mathrm{Cs}-$ bottom)

energy $H_{\mathrm{e}}(r)$ can still be negative in case of sufficiently strong electrostatic potential here [32]).

The resulting topological properties of bond critical points calculated for all studied structures are presented in Tables 2, 3, 4, and 5. In addition, in Table 6, the analogous data averaged over the same bond type are presented. One can easily see from these data, that in all of these structures, bonds can be divided into three separate groups possessing different properties: $\mathrm{C}-\mathrm{C}$ bonds (covalent; high value of electron density in bond critical point and highly negative value of Laplacian-high charge concentration in bond region), $\mathrm{C}-\mathrm{O}$ bonds (covalent with some ionic character (high electron density in bond critical point located off-center of the bond, highly negative value of Laplacian), and very weak closed shell ionic bonds between oxygen atoms and alkali metal cations (small electron density in critical point, high positive value of Laplacian indicating charge depletion). 
Bond orders

The concept of bond order has provided, for generations of chemists, a very useful tool to analyze and compare the relative strength of chemical bond. There are many different methods for calculating the bond order, both theoretical and experimental (an excellent review can be found in Jules and Lombardi [33]). The main problem with such theoretical bond orders, defined in terms of quantum mechanical properties of molecule or crystal, is the inability to easily compare the values derived from different types of bonds. One can avoid this by defining uniquely geometric (topological) parameters, which are readily identifiable and comparable for any molecule or crystal. Since Bader's QTAiM method fulfills these requirements, we have decided to use the results of topological properties of bond critical points and Cioslowski and Mixon [34] formula modified by Howard and Lamarche [35] for bond order calculations in anhydrous alkali metal oxalates (the calculated bond orders are presented in the last column of Tables 2, 3, 4, and 5).

The results presented in Tables 2, 3, 4, and 5 allow us to draw the conclusion that within an oxalate anion which interacts by electrostatic forces with alkali metal cations sub-lattice, the bonds between carbon and oxygen atoms are the strongest one in the structure, alkali metal-oxygen bonds are much weaker and carbon-carbon bonds are the weakest ones (this is confirmed by bond valence analysis presented in part II of this paper [36] where detailed analysis of the entirety of obtained results carried out from the point of view of thermal decomposition process is presented as well). The averaged values of topological properties of particular bond types in all analyzed structures presented in Table 6 show significant similarities of these properties, despite obvious differences due to respective cation properties and resulting size of cationic sub-lattice. Calculated net charges presented in Table 7 are qualitatively and quantitatively similar as well. This suggests strongly that one can expect very similar (or even the like) pathways of thermal decomposition process for all these anhydrous oxalates, which is confirmed by the experimental findings.

\section{Summary}

The results presented in this part of our paper show that electronic structure calculated by means of DFT FP-LAPW WIEN2k package and topological properties obtained from total electron density using Bader's QTAiM formalism are very similar in all six structures studied, despite the fact that two of them have different symmetry, and even if the symmetry of the remaining four structures is the same, they differ in pairs according to oxalate anion spatial conformation. Electronic structures of these compounds are typical for ionic compounds, with sharp peaks in density of states indicating very small energy bands dispersion and

Table 2 Topological properties of bond critical points in $\mathrm{Li}_{2} \mathrm{C}_{2} \mathrm{O}_{4}$ and $\mathrm{Na}_{2} \mathrm{C}_{2} \mathrm{O}_{4}$ calculated from SCF FP- LAPW total electron density: bond length $R$, Hessian matrix eigenvalues $\lambda_{1}-\lambda_{3}$, electron density in bond critical point $\rho_{\mathrm{BCP}}(r)$, Laplacian $\nabla^{2} \rho(r)$, ellipticity $\varepsilon$, electrostatic potential at BCP $V[\rho(r)]$, local electron energy density $H_{\mathrm{e}}[\rho(r)]$, and bond orders $n_{\mathrm{CM}(\mathrm{HL})}$ (Ciosłowski \& Mixon's [34] formula, optimized by Howard \& Lamarche [35])

\begin{tabular}{|c|c|c|c|c|c|c|c|c|c|c|}
\hline Bond & $\mathrm{R} / \AA$ & $\lambda_{1} / \AA^{-5}$ & $\lambda_{2} / \AA^{-5}$ & $\lambda_{3} / \AA^{-5}$ & $\rho(r) / e \AA^{-3}$ & $\nabla^{2} \rho(r) / \AA^{-5}$ & $\varepsilon$ & $V[\rho(r)] / \mathrm{au}$ & $H_{\mathrm{e}}[\rho(r)] / \mathrm{au}$ & $n_{\mathrm{CM}(\mathrm{HL}}$ \\
\hline \multicolumn{11}{|l|}{$\mathrm{Li}_{2} \mathrm{C}_{2} \mathrm{O}_{4}$} \\
\hline $\mathrm{r}_{1}\left(\mathrm{Li}-\mathrm{O}_{2}\right)$ & 1.935 & -1.088 & -1.070 & 6.798 & 0.189 & 4.642 & 0.016 & -0.147 & -0.049 & 0.85 \\
\hline $\mathrm{r}_{2}\left(\mathrm{Li}-\mathrm{O}_{1}\right)$ & 1.999 & -0.945 & -0.915 & 5.738 & 0.169 & 3.878 & 0.032 & -0.124 & -0.042 & 0.84 \\
\hline $\mathrm{r}_{3}\left(\mathrm{Li}-\mathrm{O}_{2}\right)$ & 2.033 & -0.817 & -0.815 & 5.213 & 0.159 & 3.581 & 0.003 & -0.126 & -0.045 & 0.83 \\
\hline $\mathrm{r}_{4}\left(\mathrm{Li}-\mathrm{O}_{1}\right)$ & 2.076 & -0.708 & -0.673 & 4.548 & 0.142 & 3.167 & 0.053 & -0.120 & -0.044 & 0.83 \\
\hline $\mathrm{r}_{5}\left(\mathrm{C}-\mathrm{O}_{2}\right)$ & 1.247 & -24.798 & -23.261 & 35.330 & 2.630 & -12.712 & 0.066 & -0.850 & -0.491 & 1.17 \\
\hline $\mathrm{r}_{6}\left(\mathrm{C}-\mathrm{O}_{1}\right)$ & 1.257 & -23.870 & -22.598 & 31.691 & 2.587 & -14.780 & 0.056 & -0.828 & -0.490 & 1.13 \\
\hline $\mathrm{r}_{7}(\mathrm{C}-\mathrm{C})$ & 1.559 & -12.630 & -11.216 & 9.912 & 1.657 & -13.934 & 0.126 & -1.035 & -0.590 & 0.79 \\
\hline \multicolumn{11}{|l|}{$\mathrm{Na}_{2} \mathrm{C}_{2} \mathrm{O}_{4}$} \\
\hline $\mathrm{r}_{1}\left(\mathrm{Na}-\mathrm{O}_{2}\right)$ & 2.320 & -0.633 & -0.612 & 4.376 & 0.135 & 3.130 & 0.033 & -0.158 & -0.063 & 0.82 \\
\hline$r_{2}\left(\mathrm{Na}-\mathrm{O}_{1}\right)$ & 2.331 & -0.664 & -0.655 & 4.458 & 0.143 & 3.140 & 0.014 & -0.159 & -0.063 & 0.83 \\
\hline$r_{3}\left(\mathrm{Na}-\mathrm{O}_{1}\right)$ & 2.343 & -0.664 & -0.646 & 4.328 & 0.141 & 3.020 & 0.028 & -0.153 & -0.061 & 0.82 \\
\hline $\mathrm{r}_{4}\left(\mathrm{Na}-\mathrm{O}_{2}\right)$ & 2.422 & -0.496 & -0.476 & 3.386 & 0.114 & 2.415 & 0.043 & -0.114 & -0.045 & 0.81 \\
\hline $\mathrm{r}_{5}\left(\mathrm{C}-\mathrm{O}_{2}\right)$ & 1.253 & -23.955 & -22.846 & 32.534 & 2.602 & -14.264 & 0.049 & -0.836 & -0.492 & 1.14 \\
\hline $\mathrm{r}_{6}\left(\mathrm{C}-\mathrm{O}_{1}\right)$ & 1.265 & -22.576 & -22.140 & 28.823 & 2.545 & -15.896 & 0.020 & -0.810 & -0.488 & 1.10 \\
\hline $\mathrm{r}_{7}(\mathrm{C}-\mathrm{C})$ & 1.567 & -12.228 & -10.837 & 9.876 & 1.620 & -13.190 & 0.128 & -1.026 & -0.581 & 0.78 \\
\hline
\end{tabular}


Table 3 Topological properties of bond critical points, calculated for $\mathrm{K}_{2} \mathrm{C}_{2} \mathrm{O}_{4}$ and $\beta-\mathrm{Rb}_{2} \mathrm{C}_{2} \mathrm{O}_{4}$

\begin{tabular}{|c|c|c|c|c|c|c|c|c|c|c|}
\hline Bond & $\mathrm{R} / \AA$ & $\lambda_{1} / \AA^{-5}$ & $\lambda_{2} / \AA^{-5}$ & $\lambda_{3} / \AA^{-5}$ & $\rho(r) / e \AA^{-3}$ & $\nabla^{2} \rho(r) / \AA^{-5}$ & $\varepsilon$ & $V[\rho(r)] / \mathrm{au}$ & $H_{\mathrm{e}}[\rho(r)] / \mathrm{au}$ & $n_{\mathrm{CM}(\mathrm{HL})}$ \\
\hline \multicolumn{11}{|l|}{$\mathrm{K}_{2} \mathrm{C}_{2} \mathrm{O}_{4}$} \\
\hline $\mathrm{r}_{1}\left(\mathrm{~K}-\mathrm{O}_{2}\right)$ & 2.806 & -0.336 & -0.314 & 2.150 & 0.097 & 1.500 & 0.073 & -0.054 & -0.019 & 0.80 \\
\hline $\mathrm{r}_{2}\left(\mathrm{~K}-\mathrm{O}_{2}\right)$ & 2.839 & -0.305 & -0.285 & 1.984 & 0.091 & 1.394 & 0.070 & -0.043 & -0.014 & 0.80 \\
\hline $\mathrm{r}_{3}\left(\mathrm{~K}-\mathrm{O}_{1}\right)$ & 2.842 & -0.286 & -0.269 & 1.922 & 0.085 & 1.368 & 0.062 & -0.036 & -0.011 & 0.80 \\
\hline $\mathrm{r}_{4}\left(\mathrm{~K}-\mathrm{O}_{1}\right)$ & 2.901 & -0.255 & -0.237 & 1.690 & 0.079 & 1.198 & 0.078 & -0.026 & -0.007 & 0.79 \\
\hline $\mathrm{r}_{5}\left(\mathrm{C}-\mathrm{O}_{2}\right)$ & 1.246 & -24.967 & -23.343 & 34.823 & 2.644 & -13.488 & 0.070 & -0.837 & -0.488 & 1.16 \\
\hline $\mathrm{r}_{6}\left(\mathrm{C}-\mathrm{O}_{1}\right)$ & 1.248 & -24.726 & -23.056 & 33.739 & 2.634 & -14.052 & 0.072 & -0.829 & -0.487 & 1.15 \\
\hline$r_{7}(C-C)$ & 1.595 & -11.353 & -9.960 & 9.883 & 1.532 & -11.430 & 0.140 & -0.931 & -0.525 & 0.71 \\
\hline \multicolumn{11}{|l|}{$\beta-\mathrm{Rb}_{2} \mathrm{C}_{2} \mathrm{O}_{4}$} \\
\hline $\mathrm{r}_{1}\left(\mathrm{Rb}-\mathrm{O}_{2}\right)$ & 2.960 & -0.290 & -0.268 & 1.809 & 0.091 & 1.251 & 0.084 & -0.035 & -0.011 & 0.80 \\
\hline $\mathrm{r}_{2}\left(\mathrm{Rb}-\mathrm{O}_{2}\right)$ & 2.988 & -0.270 & -0.251 & 1.702 & 0.088 & 1.180 & 0.076 & -0.026 & -0.007 & 0.79 \\
\hline $\mathrm{r}_{3}\left(\mathrm{Rb}-\mathrm{O}_{1}\right)$ & 3.018 & -0.239 & -0.222 & 1.558 & 0.079 & 1.096 & 0.078 & -0.010 & 0.001 & 0.79 \\
\hline $\mathrm{r}_{4}\left(\mathrm{Rb}-\mathrm{O}_{1}\right)$ & 3.051 & -0.234 & -0.215 & 1.481 & 0.078 & 1.033 & 0.088 & -0.004 & 0.003 & 0.79 \\
\hline $\mathrm{r}_{5}\left(\mathrm{C}-\mathrm{O}_{2}\right)$ & 1.187 & -31.666 & -29.835 & 58.031 & 2.996 & -3.451 & 0.061 & -0.946 & -0.491 & 1.42 \\
\hline $\mathrm{r}_{6}\left(\mathrm{C}-\mathrm{O}_{1}\right)$ & 1.236 & -26.051 & -24.268 & 38.655 & 2.703 & -11.674 & 0.073 & -0.837 & -0.479 & 1.20 \\
\hline $\mathrm{r}_{7}(\mathrm{C}-\mathrm{C})$ & 1.567 & -12.240 & -10.746 & 10.086 & 1.618 & -12.900 & 0.139 & -0.959 & -0.546 & 0.76 \\
\hline
\end{tabular}

Respective symbols used here are described in Table 2

Table 4 Topological properties of bond critical points, calculated for $\alpha-\mathrm{Rb}_{2} \mathrm{C}_{2} \mathrm{O}_{4}$

\begin{tabular}{|c|c|c|c|c|c|c|c|c|c|c|}
\hline Bond & $\mathrm{R} / \AA ̊$ & $\lambda_{1} / \AA^{-5}$ & $\lambda_{2} / \AA^{-5}$ & $\lambda_{3} / \AA^{-5}$ & $\rho(r) / e \AA^{-3}$ & $\nabla^{2} \rho(r) / \AA^{-5}$ & $\varepsilon$ & $V[\rho(r)] / \mathrm{au}$ & $H_{\mathrm{e}}[\rho(r)] / \mathrm{au}$ & $n_{\mathrm{CM}(\mathrm{HL})}$ \\
\hline $\mathrm{r}_{1}\left(\mathrm{Rb}_{2}-\mathrm{O}_{3}\right)$ & 2.816 & -0.362 & -0.330 & 2.526 & 0.110 & 1.834 & 0.096 & -0.075 & -0.028 & 0.80 \\
\hline $\mathrm{r}_{2}\left(\mathrm{Rb}_{1}-\mathrm{O}_{2}\right)$ & 2.888 & -0.295 & -0.280 & 2.118 & 0.094 & 1.543 & 0.054 & -0.050 & -0.017 & 0.80 \\
\hline $\mathrm{r}_{3}\left(\mathrm{Rb}_{1}-\mathrm{O}_{4}\right)$ & 2.907 & -0.345 & -0.328 & 2.106 & 0.107 & 1.433 & 0.051 & -0.046 & -0.016 & 0.80 \\
\hline $\mathrm{r}_{4}\left(\mathrm{Rb}_{1}-\mathrm{O}_{1}\right)$ & 2.953 & -0.252 & -0.237 & 1.797 & 0.084 & 1.308 & 0.066 & -0.027 & -0.006 & 0.80 \\
\hline $\mathrm{r}_{5}\left(\mathrm{Rb}_{1}-\mathrm{O}_{4}\right)$ & 3.005 & -0.229 & -0.219 & 1.586 & 0.078 & 1.137 & 0.047 & -0.010 & 0.001 & 0.79 \\
\hline $\mathrm{r}_{6}\left(\mathrm{Rb}_{2}-\mathrm{O}_{1}\right)$ & 3.030 & -0.233 & -0.221 & 1.540 & 0.083 & 1.086 & 0.058 & -0.035 & -0.012 & 0.79 \\
\hline $\mathrm{r}_{7}\left(\mathrm{Rb}_{2}-\mathrm{O}_{4}\right)$ & 3.040 & -0.227 & -0.194 & 1.493 & 0.079 & 1.071 & 0.169 & -0.033 & -0.011 & 0.79 \\
\hline $\mathrm{r}_{8}\left(\mathrm{Rb}_{2}-\mathrm{O}_{4}\right)$ & 3.042 & -0.222 & -0.215 & 1.472 & 0.080 & 1.034 & 0.034 & -0.030 & -0.010 & 0.79 \\
\hline $\mathrm{r}_{9}\left(\mathrm{Rb}_{2}-\mathrm{O}_{2}\right)$ & 3.293 & -0.125 & -0.119 & 0.857 & 0.047 & 0.613 & 0.053 & -0.011 & -0.002 & 0.79 \\
\hline $\mathrm{r}_{10}\left(\mathrm{C}_{2}-\mathrm{O}_{3}\right)$ & 1.183 & -32.004 & -31.112 & 60.080 & 3.029 & -3.020 & 0.029 & -0.955 & -0.493 & 1.44 \\
\hline $\mathrm{r}_{11}\left(\mathrm{C}_{1}-\mathrm{O}_{2}\right)$ & 1.185 & -31.184 & -31.040 & 59.357 & 3.007 & -2.868 & 0.005 & -0.960 & -0.495 & 1.43 \\
\hline $\mathrm{r}_{12}\left(\mathrm{C}_{1}-\mathrm{O}_{1}\right)$ & 1.246 & -24.220 & -24.147 & 35.426 & 2.646 & -12.932 & 0.003 & -0.823 & -0.478 & 1.17 \\
\hline $\mathrm{r}_{13}\left(\mathrm{C}_{2}-\mathrm{O}_{4}\right)$ & 1.250 & -24.485 & -23.051 & 34.414 & 2.619 & -13.122 & 0.062 & -0.810 & -0.473 & 1.16 \\
\hline$r_{14}\left(C_{1}-C_{2}\right)$ & 1.536 & -12.589 & -12.435 & 10.059 & 1.720 & -14.963 & 0.012 & -1.040 & -0.598 & 0.78 \\
\hline
\end{tabular}

Respective symbols used here are described in Table 2

almost entirely mutually exclusive occupation of energy states by alkali metal cations and electrons originating from oxalate anion constituents (carbon and oxygen atoms). On the other hand, the same states are co-occupied by carbon and oxygen $2 s$ and $2 p$ electrons, which is consistent with a picture of bonding within oxalate anion emerging from topological analysis. What is more, the respective DOS-es show significant changes in energy states occupied by alkali metal electrons, unlike in states occupied by carbon and oxygen atom electrons. This suggests that oxalate anions are well-defined entities with properties highly independent from the cationic sub-lattice. Nevertheless, one should keep in mind that ab initio calculations show that relaxed structure of oxalate anion is thermodynamically most stable, when $\mathrm{COO}^{-}$groups are not planar $\left(D_{2 \mathrm{~h}}\right.$ symmetry), but perpendicular to each other $\left(D_{2 \mathrm{~d}}\right.$ symmetry), as it is the case for cesium and $\alpha$-rubidium anhydrous oxalates. This suggests that one cannot ignore 
Table 5 Topological properties of bond critical points, calculated for $\mathrm{Cs}_{2} \mathrm{C}_{2} \mathrm{O}_{4}$

\begin{tabular}{|c|c|c|c|c|c|c|c|c|c|c|}
\hline Bond & $\mathrm{R} / \AA$ & $\lambda_{1} / \AA^{-5}$ & $\lambda_{2} / \AA^{-5}$ & $\lambda_{3} / \AA^{-5}$ & $\rho(r) / e \AA^{-3}$ & $\nabla^{2} \rho(r) / \AA^{-5}$ & $\varepsilon$ & $V[\rho(r)] / \mathrm{au}$ & $H_{\mathrm{e}}[\rho(r)] / \mathrm{au}$ & $n_{\mathrm{CM}(\mathrm{HL})}$ \\
\hline $\mathrm{r}_{1}\left(\mathrm{Cs}_{2}-\mathrm{O}_{3}\right)$ & 3.015 & -0.293 & -0.271 & 2.033 & 0.101 & 1.469 & 0.082 & -0.040 & -0.012 & 0.80 \\
\hline $\mathrm{r}_{2}\left(\mathrm{Cs}_{1}-\mathrm{O}_{1}\right)$ & 3.069 & -0.254 & -0.235 & 1.809 & 0.091 & 1.320 & 0.081 & -0.021 & -0.004 & 0.80 \\
\hline $\mathrm{r}_{3}\left(\mathrm{Cs}_{1}-\mathrm{O}_{4}\right)$ & 3.081 & -0.302 & -0.289 & 1.844 & 0.104 & 1.252 & 0.045 & -0.031 & -0.009 & 0.80 \\
\hline $\mathrm{r}_{4}\left(\mathrm{Cs}_{1}-\mathrm{O}_{4}\right)$ & 3.089 & -0.245 & -0.230 & 1.730 & 0.088 & 1.254 & 0.063 & -0.017 & -0.002 & 0.80 \\
\hline $\mathrm{r}_{5}\left(\mathrm{Cs}_{1}-\mathrm{O}_{2}\right)$ & 3.129 & -0.217 & -0.206 & 1.572 & 0.080 & 1.149 & 0.054 & -0.008 & 0.002 & 0.79 \\
\hline $\mathrm{r}_{6}\left(\mathrm{Cs}_{2}-\mathrm{O}_{4}\right)$ & 3.135 & -0.234 & -0.228 & 1.576 & 0.088 & 1.114 & 0.023 & -0.026 & -0.007 & 0.79 \\
\hline $\mathrm{r}_{7}\left(\mathrm{Cs}_{2}-\mathrm{O}_{1}\right)$ & 3.181 & -0.220 & -0.216 & 1.443 & 0.084 & 1.007 & 0.019 & -0.011 & 0.000 & 0.79 \\
\hline $\mathrm{r}_{8}\left(\mathrm{Cs}_{2}-\mathrm{O}_{4}\right)$ & 3.223 & -0.202 & -0.127 & 1.289 & 0.078 & 0.960 & 0.591 & -0.022 & -0.006 & 0.79 \\
\hline $\mathrm{r}_{9}\left(\mathrm{Cs}_{2}-\mathrm{O}_{2}\right)$ & 3.372 & -0.147 & -0.142 & 0.937 & 0.059 & 0.647 & 0.036 & -0.029 & -0.011 & 0.79 \\
\hline $\mathrm{r}_{10}\left(\mathrm{C}_{1}-\mathrm{O}_{1}\right)$ & 1.273 & -21.829 & -21.595 & 26.847 & 2.502 & -16.566 & 0.011 & -0.781 & -0.477 & 1.07 \\
\hline $\mathrm{r}_{11}\left(\mathrm{C}_{1}-\mathrm{O}_{2}\right)$ & 1.274 & -21.759 & -21.434 & 26.702 & 2.496 & -16.482 & 0.015 & -0.782 & -0.477 & 1.07 \\
\hline $\mathrm{r}_{12}\left(\mathrm{C}_{2}-\mathrm{O}_{4}\right)$ & 1.275 & -22.461 & -20.607 & 26.437 & 2.490 & -16.626 & 0.090 & -0.779 & -0.476 & 1.07 \\
\hline $\mathrm{r}_{13}\left(\mathrm{C}_{2}-\mathrm{O}_{3}\right)$ & 1.275 & -22.041 & -20.812 & 25.931 & 2.492 & -16.923 & 0.059 & -0.775 & -0.475 & 1.06 \\
\hline$r_{14}\left(C_{1}-C_{2}\right)$ & 1.560 & -11.997 & -11.734 & 9.722 & 1.654 & -14.009 & 0.022 & -0.979 & -0.562 & 0.75 \\
\hline
\end{tabular}

Respective symbols used here are described in Table 2

Table 6 Topological properties of bond critical points (electron density and its Laplacian at bond critical point), averaged over particular bond type in the structure, calculated for $\mathrm{X}_{2} \mathrm{C}_{2} \mathrm{O}_{4}(\mathrm{X}=\mathrm{Li}, \mathrm{Na}, \mathrm{K}, \beta-\mathrm{Rb}, \alpha-\mathrm{Rb}, \mathrm{Cs})$

\begin{tabular}{|c|c|c|c|c|c|c|}
\hline & \multicolumn{2}{|l|}{$\mathrm{Me}-\mathrm{O}$} & \multicolumn{2}{|l|}{$\mathrm{C}-\mathrm{O}$} & \multicolumn{2}{|l|}{$\mathrm{C}-\mathrm{C}$} \\
\hline & $\rho(r) / e \AA^{-3}$ & $\nabla^{2} \rho(r) / \AA^{-5}$ & $\overline{\rho(r) / e \AA^{-3}}$ & $\nabla^{2} \rho(r) / \AA^{-5}$ & $\rho(r) / e \AA^{-3}$ & $\nabla^{2} \rho(r) / \AA^{-5}$ \\
\hline $\mathrm{Li}_{2} \mathrm{C}_{2} \mathrm{O}_{4}$ & 0.16 & 3.817 & 2.61 & -13.746 & 1.66 & -13.934 \\
\hline $\mathrm{Na}_{2} \mathrm{C}_{2} \mathrm{O}_{4}$ & 0.13 & 2.926 & 2.57 & -15.080 & 1.62 & -13.190 \\
\hline $\mathrm{K}_{2} \mathrm{C}_{2} \mathrm{O}_{4}$ & 0.09 & 1.365 & 2.64 & -13.770 & 1.53 & -11.430 \\
\hline$\beta-\mathrm{Rb}_{2} \mathrm{C}_{2} \mathrm{O}_{4}$ & 0.08 & 1.140 & 2.85 & -7.563 & 1.62 & -12.900 \\
\hline$\alpha-\mathrm{Rb}_{2} \mathrm{C}_{2} \mathrm{O}_{4}$ & 0.08 & 1.229 & 2.83 & -7.986 & 1.72 & -14.963 \\
\hline $\mathrm{Cs}_{2} \mathrm{C}_{2} \mathrm{O}_{4}$ & 0.09 & 1.130 & 2.49 & -16.649 & 1.65 & -14.009 \\
\hline
\end{tabular}

Table 7 Bader's QTAiM atomic charges calculated for anhydrous alkali metal oxalates $\mathrm{X}_{2} \mathrm{C}_{2} \mathrm{O}_{4}$ (where $\mathrm{X}=\mathrm{Li}, \mathrm{Na}, \mathrm{K}, \beta$ - $\mathrm{Rb}, \alpha-\mathrm{Rb}, \mathrm{Cs}$ )

\begin{tabular}{|c|c|c|c|c|c|c|c|}
\hline \multicolumn{4}{|l|}{$\mathrm{Li}_{2} \mathrm{C}_{2} \mathrm{O}_{4}$} & \multicolumn{4}{|l|}{$\mathrm{K}_{2} \mathrm{C}_{2} \mathrm{O}_{4}$} \\
\hline $\mathrm{Li}$ & $\mathrm{C}$ & $\mathrm{O}_{1}$ & $\mathrm{O}_{2}$ & K & $\mathrm{C}$ & $\mathrm{O}_{1}$ & $\mathrm{O}_{2}$ \\
\hline 0.853 & 1.058 & -0.969 & -0.942 & 0.87 & 1.028 & -0.946 & -0.952 \\
\hline \multicolumn{4}{|l|}{$\mathrm{Na}_{2} \mathrm{C}_{2} \mathrm{O}_{4}$} & \multicolumn{4}{|c|}{$\beta-\mathrm{Rb}_{2} \mathrm{C}_{2} \mathrm{O}_{4}$} \\
\hline $\mathrm{Na}$ & $\mathrm{C}$ & $\mathrm{O}_{1}$ & $\mathrm{O}_{2}$ & $\mathrm{Rb}$ & $\mathrm{C}$ & $\mathrm{O}_{1}$ & $\mathrm{O}_{2}$ \\
\hline 0.884 & 1.047 & -0.971 & -0.96 & 0.886 & 1.122 & -1.028 & -0.98 \\
\hline \multicolumn{8}{|c|}{$\alpha-\mathrm{Rb}_{2} \mathrm{C}_{2} \mathrm{O}_{4}$} \\
\hline $\mathrm{Rb}_{1}$ & $\mathrm{Rb}_{2}$ & $\mathrm{C}_{1}$ & $\mathrm{C}_{2}$ & $\mathrm{O}_{1}$ & $\mathrm{O}_{2}$ & $\mathrm{O}_{3}$ & $\mathrm{O}_{4}$ \\
\hline 0.894 & 0.89 & 1.158 & 1.095 & -1.03 & -0.981 & -0.97 & -1.056 \\
\hline \multicolumn{8}{|l|}{$\mathrm{Cs}_{2} \mathrm{C}_{2} \mathrm{O}_{4}$} \\
\hline $\mathrm{Cs}_{1}$ & $\mathrm{Cs}_{2}$ & $\mathrm{C}_{1}$ & $\mathrm{C}_{2}$ & $\mathrm{O}_{1}$ & $\mathrm{O}_{2}$ & $\mathrm{O}_{3}$ & $\mathrm{O}_{4}$ \\
\hline 0.896 & 0.889 & 1.044 & 1.04 & -0.964 & -0.974 & -0.959 & -0.972 \\
\hline
\end{tabular}

entirely the influence of cationic sub-lattice, but this influence is in fact small and decreasing with increasing size of respective alkali metal cation, where such influence became negligible.
The analysis of topological properties of electron density shows that in case of all structures studied, we can distinguish three independent classes of bonds, namely covalent $\mathrm{C}-\mathrm{C}$ bonds, covalent with some ionic character 
$\mathrm{C}-\mathrm{O}$ bonds, and mainly ionic $\mathrm{Me}-\mathrm{O}$ bonds, where $\mathrm{Me}=$ $\mathrm{Li}, \mathrm{Na}, \mathrm{K}, \beta-\mathrm{Rb}, \alpha-\mathrm{Rb}, \mathrm{Cs}$. Carbon-carbon bonds are much weaker than $\mathrm{C}-\mathrm{O}$ bonds and in the light of the high flexibility in spatial position and orientation of entire oxalate anion due to its electrostatic interaction with cationic sublattice, one can safely assume that during thermal decomposition process, carbon-carbon bond will break as the first one which will lead to partial structure reconfiguration and strain relaxation and to loosening and weakening of ionic bonds between respective oxygen atoms and alkali metal cations. Thus-due to the thermally activated oscillations and rotations of $\mathrm{COO}^{-}$groups-this will allow forming of thermodynamically unstable $\left[\mathrm{OCOCO}_{2}\right]^{2-}$ transition structure, which should afterward decompose to energetically stable $\mathrm{CO}_{3}^{2-}$ anion and electrically neutral carbon oxide (II) molecule. In the second part of this paper, we will present the results of structural and bonding properties analysis performed within Bond Valence Method formalism and detailed analysis of the entirety of results presented in both parts of this paper concerning structural and bonding properties of anhydrous alkali metal oxalates under study and their relations to thermal decomposition of these compounds.

Acknowledgments This study has been supported by AGH-UST Grant No 11.11.160.110.

Open Access This article is distributed under the terms of the Creative Commons Attribution License which permits any use, distribution, and reproduction in any medium, provided the original author(s) and the source are credited.

\section{References}

1. Małecka B, Drożdż-Cieśla E, Małecki A. Mechanism and kinetics of thermal decomposition of zinc oxalate. Thermochim Acta. 2004;423:13-8.

2. Brown ME, Dollimore D, Galwey AK. Comprehensive chemical kinetics. In: Bamford $\mathrm{CH}$, Tipper $\mathrm{CFH}$, editors. Reactions in solid state, vol. 2. Amsterdam: Elsevier; 1980.

3. Boldyrev VV, Nevyantsev IS, Mikhailov YI, Khayretdinov EF. $\mathrm{K}$ voprosu o myekhanizmye tyermichyeskogo razlozhyeniya oksalatov. Kinet Katal. 1970;11:367-73.

4. Borchardt HJ, Daniels F. The application of differential thermal analysis to the study of reaction kinetics. J Am Chem Soc. 1957;79:41-6.

5. Dollimore D. The thermal decomposition of oxalates a review. Thermochim Acta. 1987;117:331-63.

6. Randhawa BS, Kaur M. A comparative study on the thermal decomposition of some transition metal maleates and fumarates. J Therm Anal Cal. 2007;89(1):251-5.

7. Galwey AK, Brown ME. An appreciation of the chemical approach of V. V. Boldyrev to the study of the decomposition of solids. J Therm Anal Cal. 2007;90(1):9-22.

8. Fujita J, Nakamoto K, Kobayashi M. Infrared spectra of metallic complexes. III. The infrared spectra of metallic oxalates. J Phys Chem. 1957;61(7):1014-5.
9. Rane S, Uskaikar H, Pednekar R, Mhalsikar R. The low temperature synthesis of metal oxides by novel hydrazine method. J Therm Anal Cal. 2007;90(3):627-38.

10. Bîrzescu M, Niculescu M, Dumitru Raluca, Carp Oana, Segal E. Synthesis, structural characterization and thermal analysis of the cobalt(II) oxalate obtained through the reaction of 1,2-ethanediol with Co(NO3)2-6H2O. J Therm Anal Cal. 2009;96(3):979-86.

11. Nopsiri Ch, Rangson M, Surasak N, Banjongchom B, Panpailin S, Naratip V. Non-isothermal kinetics of the thermal decomposition of sodium oxalate $\mathrm{Na}_{2} \mathrm{C}_{2} \mathrm{O}_{4}$. J Therm Anal Cal. 2012;107(3):1023-9.

12. Błażejowski J, Zadykowicz B. Computational prediction of the pattern of thermal gravimetry data for the thermal decomposition of calcium oxalate monohydrate. J Therm Anal Cal. 2013. doi: 10.1007/s10973-012-2934-x.

13. Koleżyński A, Małecki A. Theoretical studies of thermal decomposition of anhydrous cadmium and silver oxalates. Part I. Electronic structure calculations. J Therm Anal Cal. 2009;96(1):161-5.

14. Koleżyński A, Małecki A. Theoretical studies of thermal decomposition of anhydrous cadmium and silver oxalates. Part II. Correlations between the electronic structure and the ways of thermal decomposition. J Therm Anal Cal. 2009;96(1):167-73.

15. Koleżyński A, Małecki A. First principles studies of thermal decomposition of anhydrous zinc oxalate. J Therm Anal Cal. 2009;96(2):645-51.

16. Koleżyński A, Małecki A. Theoretical approach to thermal decomposition process of chosen anhydrous oxalates. J Therm Anal Cal. 2009;97(1):77-83.

17. Koleżyński A, Małecki A. Theoretical analysis of electronic structure and structural properties of anhydrous calcium oxalate. J Therm Anal Cal. 2009;99(2):947-55.

18. Koleżyński A, Małecki A. Theoretical analysis of electronic and structural properties of anhydrous mercury oxalate. J Therm Anal Cal. 2010;101(2):499-504.

19. Koleżyński A, Handke B, Drożdż-Cieśla E. Crystal structure, electronic structure and bonding properties of anhydrous nickel oxalate. J Therm Anal Cal. 2013. doi:10.1007/s10973-012-2844-y.

20. Bader RFW. Atoms in molecules: a quantum theory. Oxford: Clarendon Press; 1990.

21. Brown ID. The Chemical bond in inorganic chemistry. The bond valence model. Oxford: Oxford University Press; 2002.

22. Pauling L. The principles determining the structure of complex ionic crystals. J Am Chem Soc. 1929;51:1010-26.

23. Blaha P, Schwarz K, Madsen G.K.H, Kvasnicka D, Luitz J. WIEN2k, an augmented plane wave + local orbitals program for calculating crystal properties. Wien: Karlheinz Schwarz, Techn. Universität Wien. ISBN 3-9501031-1-2. 2001.

24. Slater JC. Wave functions in a periodic potential. Phys Rev. 1937;51(10):846-51.

25. Loucks TL. Augmented plane wave method. NewYork: Benjamin; 1967.

26. Andersen OK. Simple approach to the band-structure problem. Solid State Comm. 1973;13(2):133-6.

27. Hamann DR. Semiconductor charge densities with hard-core and soft-core pseudopotentials. Phys Rev Lett. 1979;42(10):662-5.

28. Wimmer E, Krakauer H, Weinert M, Freeman AJ. Full-potential self-consistent linearized-augmented-plane-wave method for calculating the electronic structure of molecules and surfaces: $\mathrm{O}_{2}$ molecule. Phys Rev B. 1981;24(2):864-75.

29. Singh DJ. Planewaves, pseudopotentials and the LAPW method. Dordrecht: Kluwer Academic Publishers; 1994.

30. Perdew JP, Burke K, Ernzerhof M. Generalized gradient approximation made simple. Phys Rev Lett. 1996;77(18):3865-8.

31. Dinnebier RE, Vensky S, Panthofer M, Jansen M. Crystal and molecular structures of alkali oxalates-first proof of a staggered oxalate anion in the solid state. Inorg Chem. 2003;42:1499-507. 
32. Tsirelson VG, Ozerov RP. Electron density and bonding in crystals. Principles, theory and X-ray diffraction experiments in solid state physics and chemistry. Bristol, UK: IOP Publishing Ltd; 1996.

33. Jules JL, Lombardi JR. Toward an experimental bond order. J Mol Struct (Teochem). 2003;664-665:255-71.

34. Cioslowski J, Mixon ST. Covalent bond orders in the topological theory of atoms in molecules. J Am Chem Soc. 1991;113(11): $4142-5$.
35. Howard ST, Lamarche O. Description of covalent bond orders using the charge density topology. J Phys Org Chem. 2003;16(2): $133-41$.

36. Koleżyński A, Małecki A. Theoretical studies of electronic structure and structural properties of anhydrous alkali metal oxalates. Part II. Electronic structure and bonding properties vs thermal decomposition pathway. J Therm Anal Cal, under review. 